\title{
Photo-degradation of di azo dye Bismarck Brown by advanced photo-Fenton process: Influence of inorganic anions and evaluation of recycling efficiency of iron powder
}

\author{
L. Gomathi Devi* , K.S. Anantha Raju, S. Girish Kumar, K. Eraiah Rajashekhar \\ Department of Chemistry, Central College City Campus, Bangalore University, Bangalore 560001, Karnataka, India
}

\section{A R T I C L E IN F O}

\section{Article history:}

Received 1 September 2009

Received in revised form 19 May 2010

Accepted 23 May 2010

\section{Keywords:}

Zero valent metallic iron

Advanced photo-Fenton process

Ammonium persulfate

Bismarck Brown

Effect of inorganic anions

Kinetic studies

\begin{abstract}
A B S T R A C T
The present research work has demonstrated the usage of zero valent metallic iron (ZVMI) in the photoFenton process under UV light as a promising and novel technique for the complete degradation of di azo dye Bismarck Brown (BB) in aqueous medium. The influence of various reaction parameters like concentration of oxidants/dye/iron powder and $\mathrm{pH}$ of the solution was investigated and optimum conditions are reported. Ammonium persulfate (APS) proved to be better oxidant in comparison with hydrogen peroxide for enhancing the degradation rate and effectively inhibited the precipitation of iron hydroxides at higher dosages of iron powder which is attributed to the acidity provided by APS which is crucial for Fenton process. The rate constant for the kinetics of degradation using various oxidation processes follows the order: $\mathrm{Fe}^{0} / \mathrm{APS} / \mathrm{UV}>\mathrm{Fe}^{0} / \mathrm{H}_{2} \mathrm{O}_{2} / \mathrm{UV}>\mathrm{Fe}^{0} / \mathrm{APS} /$ dark $>\mathrm{Fe}^{0} / \mathrm{UV}>\mathrm{Fe}^{0} / \mathrm{H}_{2} \mathrm{O}_{2} /$ dark $>\mathrm{Fe}^{0} /$ dark $>\mathrm{H}_{2} \mathrm{O}_{2} / \mathrm{UV}>\mathrm{APS} / \mathrm{UV}$. The effects of inorganic anions that are commonly found in the industrial effluents like $\mathrm{NaCl}, \mathrm{KNO}_{3}, \mathrm{Na}_{2} \mathrm{SO}_{4}, \mathrm{Na}_{2} \mathrm{CO}_{3}$ and $\mathrm{NaHCO}_{3}$ at different concentrations on the degradation rate were studied in detail. The degradation was followed by UV-vis and GC-MS techniques. (C) 2010 Taiwan Institute of Chemical Engineers. Published by Elsevier B.V. All rights reserved.
\end{abstract}

\section{Introduction}

Pollution of water by dyes is a serious problem and the removal of these dyes from wastewater is a challenge to the related industries. These synthetic dyes are stable compounds and are difficult to remove by common treatments. For the treatment of wastewater containing dye, traditional methods such as flocculation, carbon adsorption, reverse osmosis and activated sludge processes have difficulties in the complete destruction of dye pollutants and has further disadvantage of generating secondary pollution. Photo-Fenton process based on the generation of hydroxyl radicals in situ is proved to be effective way for the removal of organic pollutants in wastewater treatment (Neamtu et al., 2003; Ntampegliotis et al., 2006; Zhao et al., 2004). However the removal of sludge containing iron ions at the end of wastewater treatment is expensive and requires large amount of chemicals and needs extra manpower. Further, efficiency of the process is limited by the slow reduction of $\mathrm{Fe}^{3+}$ to $\mathrm{Fe}^{2+}$ ions in the solution. Lucking et al. tested iron powder, graphite and activated carbon for the catalytic oxidation of 4-chlorophenol in aqueous solution with hydrogen peroxide (Lucking et al., 1998). They concluded that iron powder can be used to replace iron salts as a catalyst in the Fenton

\footnotetext{
* Corresponding author. Tel.: +91 080 22961336; fax: +91 08022961331.

E-mail address: gomatidevi_naik@yahoo.co.in (L.G. Devi).
}

process which is commonly referred to as advanced photo-Fenton process (APFP).

In view of this, the present research focuses on the utilization of zero valent metallic iron powder (ZVMI) as the catalyst to mineralize synthetic dye Bismarck Brown (BB). However the disadvantage of using iron metallic powder is: (i) it requires acidic conditions; (ii) higher dosage of iron powder generates significant levels of $\mathrm{Fe}^{2+}$ ions which may cause secondary pollution; (iii) surface precipitation during the course of extended operation. To overcome these drawbacks, the present research aims at the use of low iron dosage and the experiments are designed to achieve complete mineralization of the $\mathrm{BB}$ in the desired time and thus avoiding the surface precipitation of the catalyst. The recycling efficiency of iron powder in the presence of hydrogen peroxide (HP) and ammonium persulfate (APS) is investigated.

It is well known that the dyeing processes requires the addition of inorganic salts to stabilize the color and these discharges from the dyeing baths and subsequent washing procedure contains both inorganic salts and residual dyes in the effluents. Since the reactive dyes have a lower affinity than direct dyestuffs, huge amount of inorganic salt is required when using reactive dyes in order to improve the affinity of the dyes and to enhance adsorption through "salting out" effect. The addition of these inorganic salts in the dye bath increases the pollution load in the effluent. In view of this, the influence of inorganic anions that are common in industrial effluents was explored at different concentrations. 


\section{Materials and methods}

\subsection{Materials}

Bismarck Brown (BB), iron powder (100 mesh size, at. wt. 55.55 electrolytic). The specific surface area of the powder is $7.0364 \mathrm{~m}^{2} / \mathrm{g}$ measured by dynamic Brunner-Emmet-Teller (BET) method in which $\mathrm{N}_{2}$ gas was adsorbed at $77 \mathrm{~K}$ using Digisorb 2006 surface area, pore volume analyzer Nova Quanta Chrome corporation instrument multipoint BET adsorption system. APS, $\mathrm{HP}(50 \%), \mathrm{NaCl}, \mathrm{KNO}_{3}, \mathrm{Na}_{2} \mathrm{SO}_{4}, \mathrm{Na}_{2} \mathrm{CO}_{3}$ and $\mathrm{NaHCO}_{3}$ were supplied from $\mathrm{S}$ D Fine-CHEM Limited, Bombay, India and were used as received. The molecular formula of $\mathrm{BB}$ is $\mathrm{C}_{18} \mathrm{H}_{20} \mathrm{Cl}_{2} \mathrm{~N}_{8}$ and the corresponding molecular weight is 419.32 and has $\lambda_{\max }$ at $457 \mathrm{~nm}$.

\subsection{Irradiation procedure}

APFP using ZVMI was carried out at room temperature using a circular glass reactor whose surface area is $176 \mathrm{~cm}^{2}$. Artificial light source used in the present study is $125 \mathrm{~W}$ medium pressure mercury vapor lamp. The photon flux of the light source is $7.75 \mathrm{~mW} / \mathrm{cm}^{2}$ as determined by ferrioxalate actinometry, the wavelength of which peaks around 350-400 nm and the maximum emission is at $370 \mathrm{~nm}$. The lamp was warmed for $10 \mathrm{~min}$ to reach constant output. The irradiation was carried out by directly focusing the light into the reaction mixture in open-air condition at a distance of $29 \mathrm{~cm}$. In a typical experiment, $250 \mathrm{ml}$ of the dye solution was used and $\mathrm{pH}$ of the solution was adjusted either by adding dilute $\mathrm{NaOH}$ or dilute $\mathrm{H}_{2} \mathrm{SO}_{4}$.

\subsection{Analytical methods}

The sample solution $(5 \mathrm{ml})$ was taken out from the reactor at definite time intervals and centrifuged. The centrifugate were analyzed by UV-vis spectroscopic technique using Shimadzu UV1700 Pharmaspec UV-vis spectrophotometer. The centrifugate were extracted into non-aqueous medium and $1 \mu l$ was subjected to GC-MS analysis (using GC-MS-QP-5000 Shimadzu) and Thermo Electron Trace GC ultra coupled to a DSQ mass spectrometer equipped with an Alltech ECONO-CAP-EC-5 capillary column $(30 \mathrm{~m} \times 0.25 \mathrm{~mm}$ i.d. $\times 0.25 \mathrm{~mm}$ film thickness) was used. Pure helium was used as the carrier gas at a flow rate of $1.2 \mathrm{ml} / \mathrm{min}$. The injector/transfer line/trap temperature was $220 / 250 / 200{ }^{\circ} \mathrm{C}$, respectively. Electron impact ionization was carried out at $70 \mathrm{eV}$. The well defined iron particles without agglomeration was confirmed by scanning electron microscope (Fig. 1). EDX confirmed the presence of $\mathrm{Fe}$ (96.27), $\mathrm{Si}(0.26)$ and $\mathrm{O}$ (2.54) in wt.\% in the used iron powder.

\subsection{Calculation of quantum efficiency ( $\Phi)$}

The quantum efficiency can be defined as the concentration of the pollutant degraded divided by the amount of energy in terms of intensity and exposure surface area per time:

$\Phi=\frac{C_{0}-C}{t I S}$

$C_{0}$ is the initial concentration of the dye substrate and $C$ is the concentration at time ' $t$ ' and $\left(C_{0}-C\right)$ denotes the residual concentration of the dye in ppm. ' $T$ ' is the irradiation intensity $\left[I=\right.$ Einstein $/ \mathrm{m}^{2} \mathrm{~s}=8.36 \times \lambda(\mathrm{nm}) \times$ power $\left.(\mathrm{W})\right] \quad$ (where $\lambda$ is $370 \mathrm{~nm}$ and power is $125 \mathrm{~W}$ ). ' $S$ ' denotes the solution irradiated plane surface area in $\mathrm{cm}^{2}$ and ' $t$ ' represents the irradiation time in minutes.
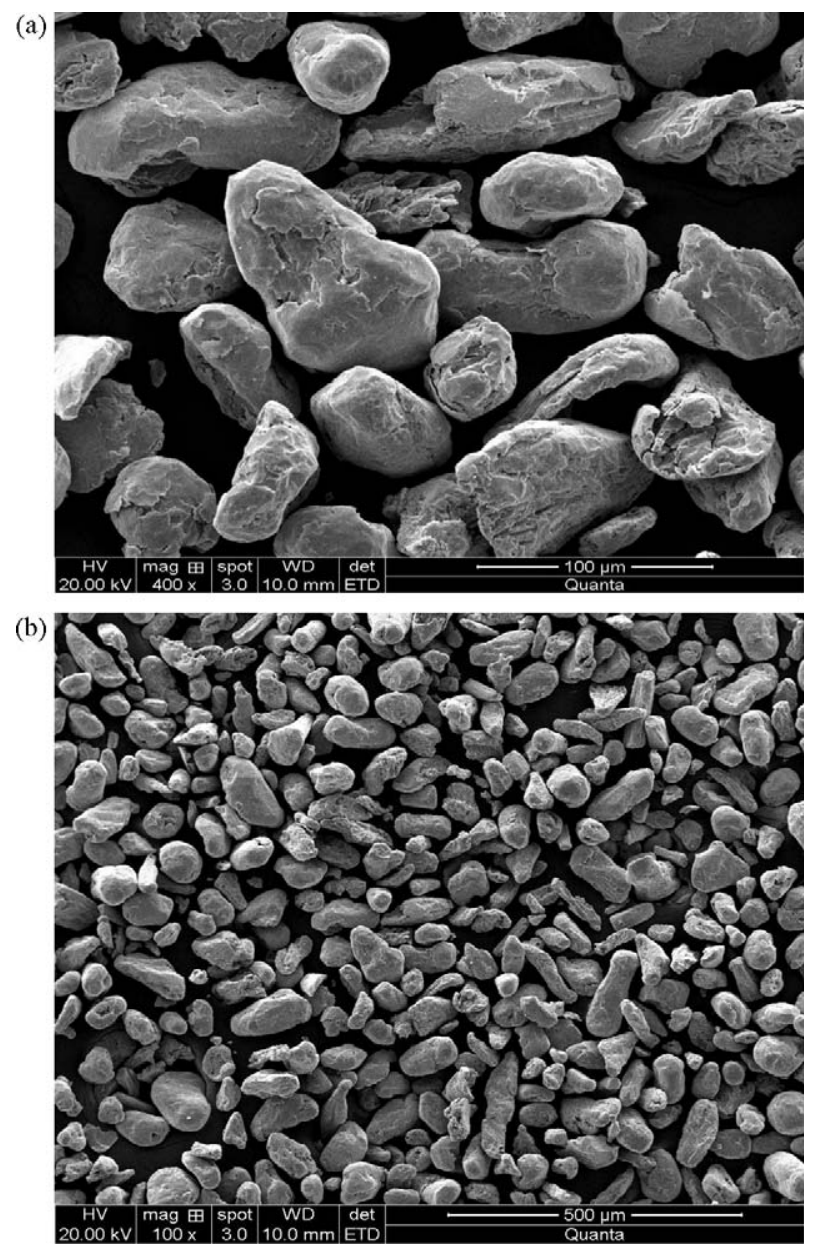

Fig. 1. SEM image of 100 mesh size iron powder: (A) 400 and (B) 100 magnification.

\section{Results and discussions}

Iron surface gets oxidized in acidic medium to form ferrous ions $\left(\mathrm{Fe}^{2+}\right)$. Alternatively $\mathrm{Fe}^{2+}$ ions can also be generated by the reaction of iron surface with the oxidant $\mathrm{H}_{2} \mathrm{O}_{2}$ which are partially adsorbed on the iron surface. These adsorbed $\mathrm{Fe}^{2+}$ ions can further react with $\mathrm{H}_{2} \mathrm{O}_{2}$ generating hydroxyl radicals:

$\mathrm{Fe}^{0}+\mathrm{H}_{2} \mathrm{O}_{2} \rightarrow \mathrm{Fe}^{2+} \ldots$. . surface

$\mathrm{Fe}^{2+} \ldots$. surface $+\mathrm{H}_{2} \mathrm{O}_{2} \rightarrow \mathrm{Fe}^{3+}+\mathrm{HO}^{\bullet}+\mathrm{HO}^{-}$

If these $\mathrm{Fe}^{2+}$ ions are not partially adsorbed, they can diffuse into the bulk of the solution generating hydroxyl anions. $\mathrm{Fe}^{\mathrm{O}}$ initially oxidizes to $\mathrm{Fe}^{2+}$ by losing two electrons as shown in Eq. (4). These two electrons are transferred to electron acceptors like $\mathrm{H}_{2} \mathrm{O}_{2}$ which can form two hydroxide ions as shown in Eq. (5). By combining Eqs. (4) and (5) we get the resultant Eq. (6):

$\mathrm{Fe}^{0} \stackrel{\mathrm{H}^{+}}{\longrightarrow} \mathrm{Fe}^{2+}+2 e^{-}$

$\mathrm{H}_{2} \mathrm{O}_{2}+2 e^{-} \rightarrow 2 \mathrm{OH}^{-}$

$\mathrm{Fe}^{0}+\mathrm{H}_{2} \mathrm{O}_{2} \rightarrow \mathrm{Fe}^{2+}+2 \mathrm{HO}^{-}$

The oxidant APS reacts with iron surface leading to the formation of sulfate and ferrous ions:

$\mathrm{Fe}^{0}+\mathrm{S}_{2} \mathrm{O}_{8}^{2-} \rightarrow \mathrm{Fe}^{2+}+2 \mathrm{SO}_{4}^{2-}$ 
The $\mathrm{Fe}^{2+}$ ions can further react with the oxidant molecules to generate free radicals by oxidizing itself to form $\mathrm{Fe}^{3+}$ ions.

$\mathrm{Fe}^{2+}+\mathrm{H}_{2} \mathrm{O}_{2} \rightarrow \mathrm{Fe}^{3+}+\mathrm{OH}^{\bullet}+\mathrm{OH}^{-}$

$\mathrm{Fe}^{2+}+\mathrm{S}_{2} \mathrm{O}_{8}^{2-} \rightarrow \mathrm{Fe}^{3+}+\mathrm{SO}_{4}^{2-}+\mathrm{SO}_{4}^{-\bullet}$

In Eq. (3), $\mathrm{Fe}^{2+}$ ions are formed on the solid iron surface, which reacts with the oxidizing agent whose rate constant is $6 \times 10^{-2} \mathrm{M}^{-1} \mathrm{~S}^{-1} / \mathrm{s}$, while in Eq. (8) it is the free $\mathrm{Fe}^{2+}$ ions in the solution that reacts with the oxidant (rate constant is $76 \mathrm{M}^{-1} \mathrm{~S}^{-1} \mathrm{~s}$ ). Though the nature of the products remains same in both the cases, the rate of formation of $\mathrm{Fe}^{3+}$ ions is faster than Eq. (8) in the homogeneous condition (Kusic et al., 2006).

Ferric ions $\left(\mathrm{Fe}^{3+}\right)$ so formed can either react with molecules of water or $\mathrm{H}_{2} \mathrm{O}_{2}$ as represented in the following way:

(i) Ferric ions $\left(\mathrm{Fe}^{3+}\right)$ on reaction with water form an aqua complex. This complex under UV irradiation generates $\mathrm{Fe}^{2+}$ ions and hydroxyl radicals:

$$
\begin{aligned}
& \mathrm{Fe}^{3+}+\mathrm{H}_{2} \mathrm{O} \Leftrightarrow\left[\mathrm{Fe}(\mathrm{OH})^{2+}\right]+\mathrm{H}^{+} \\
& {\left[\mathrm{Fe}(\mathrm{OH})^{2+}\right]+h v \rightarrow \mathrm{Fe}^{2+}+\mathrm{HO}^{\bullet}}
\end{aligned}
$$

(ii) $\mathrm{Fe}^{3+}$ ions can also react with $\mathrm{H}_{2} \mathrm{O}_{2}$ leading to the formation of $\mathrm{Fe}^{2+}$ ions along with hydroperoxyl radicals. Further these radicals so formed have the ability to reduce $\mathrm{Fe}^{3+}$ ions, generating hydroxyl radicals. The $\mathrm{Fe}^{2+}$ ions are thus formed in two stages can actively participate in the cyclic Fenton process:

$$
\begin{aligned}
& \mathrm{Fe}^{3+}+\mathrm{H}_{2} \mathrm{O}_{2} \rightarrow \mathrm{Fe}^{2+}+\mathrm{H}^{+}+\mathrm{HO}_{2} \bullet \\
& \mathrm{Fe}^{3+}+\mathrm{HO}_{2} \bullet \mathrm{Fe}^{2+}+\mathrm{O}_{2}+\mathrm{H}^{+}
\end{aligned}
$$

Two molecules of sulfate radicals are produced when $\mathrm{Fe}^{3+}$ reacts with persulfate anion, which generates hydroxyl radicals on reaction with water molecule (Devi et al., 2009).

$$
\begin{aligned}
& \mathrm{Fe}^{3+}+\mathrm{S}_{2} \mathrm{O}_{8}^{2-} \rightarrow \mathrm{Fe}^{3+}+2 \mathrm{SO}_{4}^{-} \\
& \mathrm{SO}_{4}^{-} \cdot+\mathrm{H}_{2} \mathrm{O} \rightarrow \mathrm{SO}_{4}^{2-}+\mathrm{OH}^{\bullet}+\mathrm{H}^{+}
\end{aligned}
$$

In order to determine the efficiency of photo-Fenton process, the experiments were carried out in the dark. The extent of dye degradation was only 32 and 45 percent for $\mathrm{Fe}^{0} / \mathrm{H}_{2} \mathrm{O}_{2}$ and $\mathrm{Fe}^{0} / A P S$ processes, respectively in the dark condition for 1 -h duration. The complete degradation takes place efficiently in the presence of UV light. This can be accounted to the photo-reduction process of aqueous $\mathrm{Fe}^{3+}$ to $\mathrm{Fe}^{2+}$ (rate determining step in the dark) takes place at a faster rate (Ntampegliotis et al., 2006):

$\mathrm{Fe}^{3+}+h v \rightarrow \mathrm{Fe}^{2+}$

Further the regeneration of $\mathrm{Fe}^{2+}$ ions on iron surface takes place at a faster rate which additionally contributes to overall efficiency (Bremner et al., 2006):

$2 \mathrm{Fe}^{3+}+\mathrm{Fe}^{0} \rightarrow 3 \mathrm{Fe}^{2+}$

Photolysis of oxidants leading to the formation of various ions and highly oxidative radicals under UV light additionally contributes for overall efficiency of the process.

\subsection{Effect of $p H$}

The pollutants can be decolorized efficiently in photo-Fenton process only under acidic conditions (Kang et al., 2002). When the $\mathrm{pH}$ of the solution was increased from 1.5 to 3 , the degradation efficiency also increased from 28 to 100 percent. The degradation rate constant for the process $\mathrm{Fe}^{0} / \mathrm{H}_{2} \mathrm{O}_{2} / \mathrm{UV}$ calculated at $\mathrm{pH} 3$ is found to be $3.84 \times 10^{-2} \mathrm{~min}^{-1}$ which is almost 4.2 times higher than the value calculated at $\mathrm{pH} 1.0\left(0.91 \times 10^{-2} \mathrm{~min}^{-1}\right)$. Similarly for $\mathrm{Fe}^{0} / \mathrm{APS} / \mathrm{UV}$ process, the rate constant calculated at $\mathrm{pH} 3$ is $7.91 \times 10^{-2} \mathrm{~min}^{-1}$. At $\mathrm{pH} \mathrm{3}$, the dominating photoactive species $\mathrm{Fe}^{3+}$ and $\mathrm{Fe}[\mathrm{OH}]^{2+}$ complex ions are found in equal proportion which have largest light absorption coefficient and show high quantum yield for hydroxyl radical generation, along with regeneration of $\mathrm{Fe}^{2+}$ ions in the wavelength range of 280$370 \mathrm{~nm}$ (Katsumata et al., 2004). The change in this optimum $\mathrm{pH}$ leads to decrease in the concentration of $\mathrm{Fe}[\mathrm{OH}]^{2+}$ complexes and it can also result in the precipitation of ferrous ion as oxy hydroxides. The various photoactive species of iron formed at different $\mathrm{pH}$ conditions are: $\mathrm{Fe}\left[\mathrm{H}_{2} \mathrm{O}\right]_{6}{ }^{3+}(\mathrm{pH} \mathrm{1-2})$, Fe $[\mathrm{OH}]\left[\mathrm{H}_{2} \mathrm{O}\right]_{5}{ }^{2+}$ (pH 2-3) and $\mathrm{Fe}[\mathrm{OH}]_{2}\left[\mathrm{H}_{2} \mathrm{O}_{4}{ }^{+}\right.$( $\mathrm{pH} \mathrm{3-4)} \mathrm{(Neamtu} \mathrm{et} \mathrm{al.,} \mathrm{2003).} \mathrm{The}$ lower rate constant at $\mathrm{pH} 1.0$ is mainly due to the excess $\mathrm{H}^{+}$ions in the solution acting as hydroxyl radical scavenger:

$\mathrm{H}^{+}+\mathrm{OH}^{\bullet}+e^{-} \rightarrow \mathrm{H}_{2} \mathrm{O}$

Beyond this optimum $\mathrm{pH}$ 3, degradation efficiency decreases as shown in Fig. 2. At $\mathrm{pH}(\geq 7)$, dye almost resists degradation. Beyond $\mathrm{pH} 3$, the concentration of hydroxyl anion increases at the expense of concentration of photoactive complex. The excess hydroxide anion combines with $\mathrm{Fe}^{3+}$ ion forming photo-inactive $\mathrm{Fe}(\mathrm{OH})_{3}$ thus reducing the generation of hydroxyl radicals in the solution. This is due to the coagulation of $\mathrm{Fe}^{3+}$ complex molecules formed in the reaction which inhibits the catalytic reaction of $\mathrm{Fe}^{2+}$ ions with the oxidants. At high $\mathrm{pH}$, precipitation of iron oxyhydroxides takes place and this precipitate gets deposited on the iron surface which blocks the electron transfer between the catalyst and oxidant, thereby reducing the generation of hydroxyl radicals in the solution. Therefore APFP experiments were optimized at $\mathrm{pH} 3$.

\subsection{Effect of oxidants}

The present study investigates the application of $\mathrm{HOOH}$ (hydrogen peroxide) and $\mathrm{S}_{2} \mathrm{O}_{8}{ }^{2-}$ (peroxy disulfate) which are symmetrical peroxides and can act as potential oxidants in the light induced reaction processes. Persulfate anion can also generate free radicals like sulfate and hydroxyl radicals which provide free radical mechanism similar to hydroxyl radical pathways generated in the Fenton's chemistry. Sulfate radical is one of the strongest

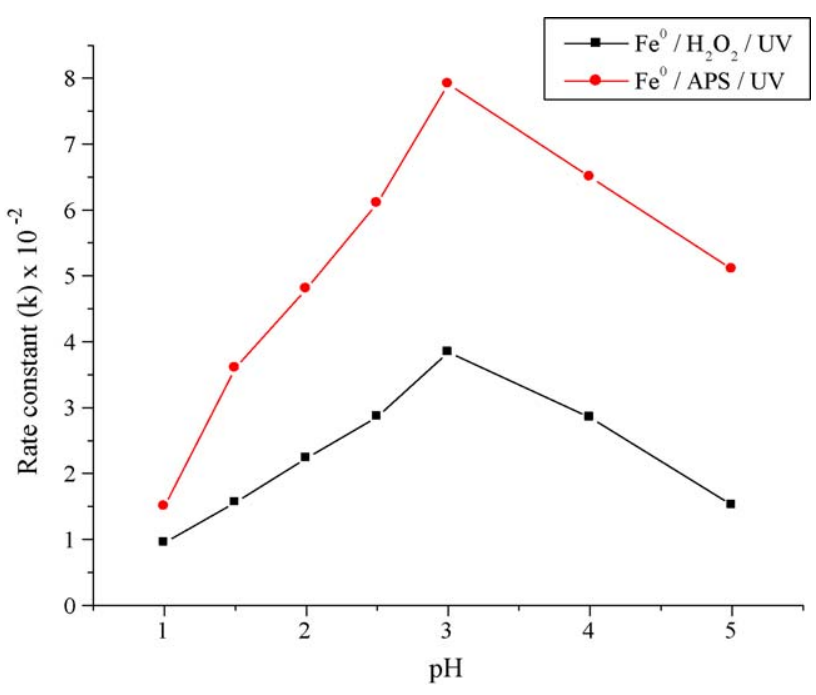

Fig. 2. Influence of $\mathrm{pH}$ on APFP. Experimental condition: $\left[\mathrm{Fe}^{0}\right]=10 \mathrm{mg} / 250 \mathrm{ml}$, $[\mathrm{BB}]=25 \mathrm{ppm},[\mathrm{HP}]=25 \mathrm{ppm}$ or $[\mathrm{APS}]=10 \mathrm{ppm}$ and $\mathrm{pH} 3$. 


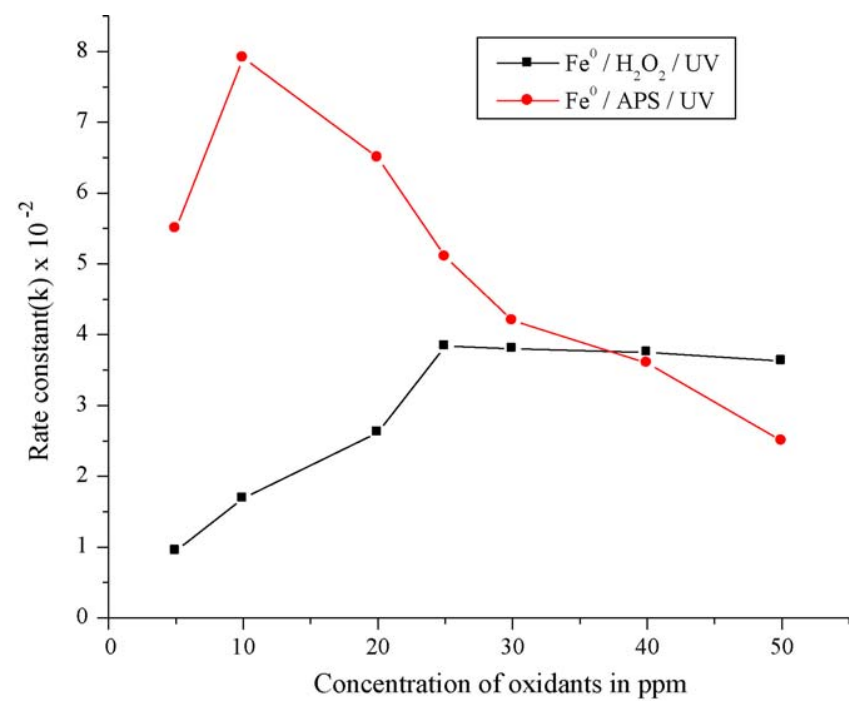

Fig. 3. Plot of rate constant versus concentration of oxidants in ppm. Experimental condition: $\left[\mathrm{Fe}^{0}\right]=10 \mathrm{mg} / 250 \mathrm{ml},[\mathrm{BB}]=25 \mathrm{ppm}$ and $\mathrm{pH} 3$.

oxidizing species in aqueous media with a redox potential of $2.6 \mathrm{~V}$ which is next only to the hydroxyl free radical whose redox potential is $2.8 \mathrm{~V}$. The sulfate radical anions produced in the case of APS show various possible reaction mechanism in the process of mineralization: (i) abstraction of hydrogen atom from the saturated carbon; (ii) capable of adding to the unsaturated compounds; (iii) it can remove an electron from the anions and neutral molecules (Neta et al., 1977). These attributes combine to make persulfate a viable option for the chemical oxidation of a broad range of contaminants.

The influence of oxidants on the degradation was investigated by maintaining the other reaction parameters constant. When the concentration of HP was $25 \mathrm{ppm}$, the rate constant for the degradation is $3.84 \times 10^{-2} \mathrm{~min}^{-1}$ (Fig. 3). Beyond this concentration, rate constant decreases. This can be due to the recombination of excess hydroxyl radicals generated or it might get involved in the unwanted reaction pathways like generation of less reactive hydro peroxyl radicals and competitive reaction between hydroperoxyl radicals and dye molecules with hydroxyl radicals. (Baxendale and Wilson, 1957; Elmorsi et al., 2010):

$\mathrm{H}_{2} \mathrm{O}_{2}+\mathrm{OH}^{\bullet} \rightarrow \mathrm{O}_{2} \mathrm{H}^{\bullet}+\mathrm{H}_{2} \mathrm{O}$

$\mathrm{O}_{2} \mathrm{H}^{\bullet}+\mathrm{OH}^{\bullet} \rightarrow \mathrm{H}_{2} \mathrm{O}+\mathrm{O}_{2}$

$2 \mathrm{OH}^{\bullet} \rightarrow \mathrm{H}_{2} \mathrm{O}_{2}$

Similar experiments were carried out with APS and its optimum concentration was found to be $10 \mathrm{ppm}$ and the rate constant is $7.91 \times 10^{-2} \mathrm{~min}^{-1}$ as shown in Fig. 2. In the case of APS, we speculate that the hydroxyl radicals generated might react with sulfate anion generating less active sulfate radical and hydroxyl anion:

$\mathrm{SO}_{4}^{2-}+\mathrm{OH}^{\bullet} \rightarrow \mathrm{OH}^{-}+\mathrm{SO}_{4}^{-\bullet}$

The rate constant calculated for the process $\mathrm{Fe}^{0} / \mathrm{APS} / \mathrm{UV}$ is two times higher than $\mathrm{Fe}^{0} / \mathrm{HP} / \mathrm{UV}$ process. This is mainly due to the influence of oxidants on the final $\mathrm{pH}$ of the reaction which can be explained as follows: The final $\mathrm{pH}$ of the solution was found to be 3.6 with $\mathrm{HP}$ (25 ppm), while the final $\mathrm{pH}$ was reduced to 2.9 for APS $(10 \mathrm{ppm})$. Since APS provides better acidic $\mathrm{pH}$ necessary for Fenton process, it accelerates the rate of the reaction compared to $\mathrm{H}_{2} \mathrm{O}_{2}$. The acidity maintained with APS increases the concentration of $\mathrm{Fe}^{2+}$ ions in the bulk of the solution due to the dissolution of iron powder which enhances the generation of hydroxyl radicals. With increase in the concentration of APS to $50 \mathrm{ppm}$, the $\mathrm{pH}$ of the solution after $30 \mathrm{~min}$ of $\mathrm{UV}$ irradiation is 2.12 and the rate constant drastically decreases to $2.55 \times 10^{-2} \mathrm{~min}^{-1}$. The excess acidity increases the concentration of protons in the solution which acts as hydroxyl radical scavenger. However, the rate constant still remains almost same even for higher concentration of $\mathrm{HP}$ (50 ppm) and the final $\mathrm{pH}$ of the reaction mixture was $\sim 3.7$.

\subsection{Effect of catalyst loading}

The optimization of the catalyst concentration is a necessary step in the photo-Fenton reaction mechanism. The degradation efficiency was found to be 18 and 13 percent, respectively with $\mathrm{H}_{2} \mathrm{O}_{2} / \mathrm{UV}$ and APS/UV process for $1 \mathrm{~h}$ of irradiation. This is due to the direct photolysis of oxidants in the presence of UV light. However complete degradation with higher efficiency was achieved by the use of iron surface in the presence of oxidants. The iron surface catalytically decomposes the oxidants to respective free radicals/ions at a faster rate to generate more hydroxyl radicals under UV light. In contrast, overloading of the catalyst hinders the degradation efficiency. This may be attributed due to the following reasons: (i) higher concentration of the catalyst results in turbidity which hinders the penetration of UV light. (ii) High dosage of iron powder increases the concentration of $\mathrm{Fe}^{2+}$ ions in the solution which can also act as hydroxyl radical scavenger (Barbusinski and Majewski, 2003):

$\mathrm{Fe}^{2+}+\mathrm{OH}^{\bullet} \rightarrow \mathrm{Fe}^{3+}+\mathrm{OH}^{-}$

The increase in the dosage of iron powder shifts the reaction medium from acidic to alkaline condition which affects the degradation rate (Fig. 4). The shift in the pH depends mainly on the nature of the oxidants which can be explained as follows: when the catalyst loading was varied from 10 to $20 \mathrm{mg}$, the final $\mathrm{pH}$ of the reaction mixture is 3.6 with $\mathrm{H}_{2} \mathrm{O}_{2}$ as an oxidant. When the catalyst concentration is increased to $150 \mathrm{mg}$, $\mathrm{pH}$ of the solution changes to 4.8. At this condition, turbidity in the reaction mixture is observed. With further increase in the catalyst loading $200 \mathrm{mg}$, excess iron precipitates as iron oxy hydroxides and the precipitate separates from the true solution and the $\mathrm{pH}$ of the solution shifts to 5.75. At this $\mathrm{pH}$, the concentration of hydroxyl anion increases at the expense of concentration of photoactive complex Fe $[\mathrm{OH}]\left[\mathrm{H}_{2} \mathrm{O}\right]_{5}{ }^{2+}$.

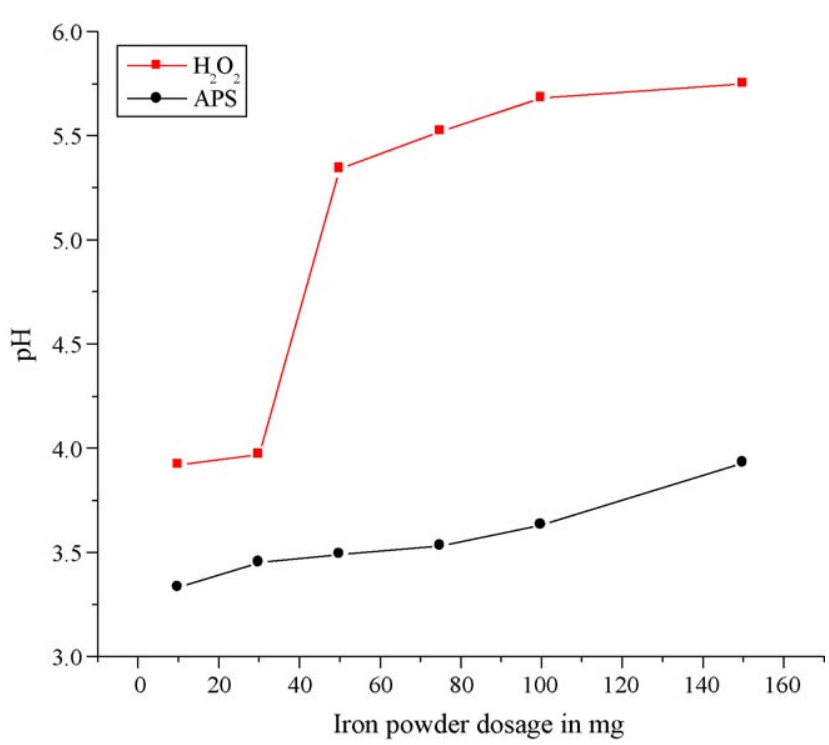

Fig. 4. Variation in $\mathrm{pH}$ as a function of iron powder dosage using different oxidants. Experimental condition: $[\mathrm{BB}]=25 \mathrm{ppm},[\mathrm{HP}]=25 \mathrm{ppm}$ or $[\mathrm{APS}]=10 \mathrm{ppm}$ and $\mathrm{pH} 3$. 
Table 1

Percentage degradation and rate constant for different initial concentration of BB using HP/APS oxidant.

\begin{tabular}{lrll}
\hline APFP & {$[\mathrm{BB}]$} & $\begin{array}{l}\text { Percentage } \\
\text { degradation }\end{array}$ & $\begin{array}{l}\text { Rate constant } \\
\left(\times 10^{-2} / \mathrm{min}\right)\end{array}$ \\
\hline $\mathrm{Fe}^{0} / \mathrm{HP} / \mathrm{UV}$ (60 min) & 25 & 100 & 3.84 \\
& 50 & 78 & 2.78 \\
& 100 & 55 & 1.45 \\
$\mathrm{Fe}^{0} / \mathrm{APS} / \mathrm{UV}$ (30 min) & 25 & 100 & 7.91 \\
& 50 & 56 & 5.91 \\
& 100 & 30 & 1.19
\end{tabular}

Experimental condition: $\left[\mathrm{Fe}^{0}\right]=10 \mathrm{mg} / 250 \mathrm{ml},[\mathrm{BB}]=25 \mathrm{ppm},[\mathrm{HP}]=25 \mathrm{ppm}$ or $[\mathrm{APS}]=10 \mathrm{ppm}$ and $\mathrm{pH} 3$.

The excess hydroxide anion combines with $\mathrm{Fe}^{3+}$ ion forming photoinactive $\mathrm{Fe}(\mathrm{OH})_{3}$ thus reducing the generation of hydroxyl radicals in the solution. However with APS final $\mathrm{pH}$ of the reaction medium was 3.93, for higher concentration of iron powder $(150 \mathrm{mg})$ and no turbidity in the reaction solution was observed. Hence it can be concluded that APS effectively inhibits the process of precipitation of iron powder by providing excess acidity to the reaction medium.

\subsection{Effect of initial dye concentration}

In the photo-Fenton process, change in the dye concentration affects the degradation process significantly. Therefore experiments were performed at different initial dye concentrations by maintaining the other reaction parameters constant. The calculated values of percentage degradation and the rate constant for different initial concentration of the dye along with the oxidants are shown in the Table 1 . Beyond the optimum concentration $(25 \mathrm{ppm})$, the extent of degradation decreases to 55 percent for higher initial dye concentration (100 ppm). This may be due to the fact that, as the dye concentration is increased, the number of hydroxyl radicals is not increased proportionally. High dye concentration prevents the UV light penetration into the depth of the solution there by decreasing the generation of hydroxyl radicals (Dutta et al., 2001). Moreover at high concentrations, the active centers on the iron surface will be occupied by the dye molecules which are capable of reducing the catalyst surface itself by hindering the generation of hydroxyl radicals. The process $\mathrm{Fe}^{0} /$ $\mathrm{H}_{2} \mathrm{O}_{2}$ /UV showed higher efficiency for the degradation of higher initial dye concentration compared to $\mathrm{Fe}^{0} / \mathrm{APS} / \mathrm{UV}$ process. Since quantum efficiency involves term ' $I$ ' (intensity of UV lamp), the measure of quantum efficiency inversely relates the ability of color wastewater to absorb UV photons. The low quantum efficiency at higher dye concentration indicates the fact that, intense color solution can act as inner filter which prevents the UV light photons reaching to the surface of the photocatalyst. This might inhibit cyclic photo-Fenton reactions resulting in low rate constant.

\subsection{Effect of hydroxyl radical scavenger}

The role of hydroxyl radicals in the oxidation of dye by photoFenton process was confirmed by carrying the degradation process in the presence of hydroxyl radical scavenger like methyl alcohol. Methyl alcohol is known to deactivate hydroxyl radical and its derivatives. Methanol reacts with hydroxyl radical and to a lesser extent with hydrogen radical whose second order rate constants are $9.7 \times 10^{8}$ and $2.6 \times 10^{6} \mathrm{~mol} / \mathrm{s}$, respectively (Eqs. (20) and (21)):

$\mathrm{CH}_{3} \mathrm{OH}+\bullet \cdot \mathrm{OH} \rightarrow \mathrm{CH}_{3} \mathrm{O}^{\bullet}+\mathrm{H}_{2} \mathrm{O}$

$\mathrm{CH}_{3} \mathrm{OH}+{ }^{\bullet} \mathrm{H} \rightarrow \mathrm{CH}_{3} \mathrm{O}^{\bullet}+\mathrm{H}_{2}$

The rate constant, quantum efficiency $(\Phi)$ and the percentage degradation in the presence and in the absence of methyl alcohol are shown in Table 2. Color removal is 100 percent in the absence of methyl alcohol. The efficiency decreased to 54 and 70 percent for $1 \mathrm{~h}$ of irradiation in the presence of methyl alcohol with HP and APS (Table 2). The decreasing effect is more for HP compared to the APS. This is due to the inability of methyl alcohol to deactivate sulfate radicals which mediates the degradation in the absence of hydroxyl radicals. Neta et al. reported that sulfate radicals participate in the degradation either by electron abstraction or by adding to unsaturated atoms. These results provide an evidence for the role of hydroxyl and sulfate radicals in the degradation mechanism. Also, it should be noted that APS serves as better oxidant even in the presence of hydroxyl radical scavenger.

\subsection{Effect of inorganic anions}

The effect of inorganic anions on the rate of degradation is shown in Tables 3 and 4 for HP and APS. All the anions showed relative tendency to quench the hydroxyl radicals thus affecting the degradation rate. The extent of quenching of hydroxyl radicals is found to be strongly dependent on nature of anions, its concentration and on the oxidant used. Three different concentrations of anions were used to study their behavior with respect to the oxidizing agent. If the concentration of anion is $\leq \mathrm{HP}(\leq 25 \mathrm{ppm})$ the sequence follows the same order except the fact that carbonate anions shows least quenching effect when its concentration is lower than HP. While nitrate anions shows least influence on the degradation kinetics when its concentration is same as that of HP. It is interesting to note that sulfate and chloride anion has a significant influence for quenching the hydroxyl radicals over the range of concentration used. The chloride and sulfate anions can form strong complex with $\mathrm{Fe}^{2+} / \mathrm{Fe}^{3+}$ ions thereby reducing concentration of free iron ions in the solution which are necessary for Fenton mechanism (Schemes 1-2) (Orozco et al., 2008). These anions can quench the hydroxyl radicals which further affect the degradation rate. Carbonate, bicarbonate and nitrate anions do not have tendency to form complex with iron ions in the solution (Pappolymerou et al., 2007). They can only scavenge the hydroxyl radicals in the solution as shown in Scheme 3. Hence influence of these anions on the degradation kinetics is low even at higher concentrations. The presence of inorganic anions can reduce the electrostatic repulsion between dye molecules which leads to aggregation making it less susceptible to hydroxyl radical attack (Dong et al., 2007):

Table 2

Percentage degradation, rate constant and quantum efficiency $(\Phi)$ in the presence and in the absence of methyl alcohol for the optimized experiments.

\begin{tabular}{|c|c|c|c|c|c|c|}
\hline \multirow[t]{2}{*}{ Advanced Fenton process } & \multicolumn{2}{|c|}{ Percentage degradation } & \multicolumn{2}{|c|}{ Rate constant $\left(\times 10^{-2} / \mathrm{min}\right)$} & \multicolumn{2}{|c|}{$\begin{array}{l}\text { Quantum efficiency }(\Phi) \\
\left(\times 10^{-12} / \mathrm{ppm} / \text { Einstein }\right)\end{array}$} \\
\hline & Without $\mathrm{CH}_{3} \mathrm{OH}$ & With $\mathrm{CH}_{3} \mathrm{OH}$ & Without $\mathrm{CH}_{3} \mathrm{OH}$ & With $\mathrm{CH}_{3} \mathrm{OH}$ & Without $\mathrm{CH}_{3} \mathrm{OH}$ & With $\mathrm{CH}_{3} \mathrm{OH}$ \\
\hline $\mathrm{Fe}^{0} / \mathrm{UV} / \mathrm{HP}$ & 100 & 54 & 3.84 & 1.26 & 24.3 & 13.2 \\
\hline $\mathrm{Fe}^{0} / \mathrm{UV} / \mathrm{APS}$ & 100 & 70 & 7.91 & 4.16 & 48.6 & 34.0 \\
\hline
\end{tabular}

Experimental condition: $\left[\mathrm{Fe}^{0}\right]=10 \mathrm{mg} / 250 \mathrm{ml},[\mathrm{BB}]=25 \mathrm{ppm},[\mathrm{HP}]=25 \mathrm{ppm}$ or $[\mathrm{APS}]=10 \mathrm{ppm}, 1 \mathrm{ml}$ of $\mathrm{CH}_{3} \mathrm{OH}$ and $\mathrm{pH} 3$. 
Table 3

Rate constant and process efficiency in the presence of various inorganic anions for the process of $\mathrm{Fe}^{\mathrm{O}} / \mathrm{HP} / \mathrm{UV}$.

\begin{tabular}{llll}
\hline $\begin{array}{l}\text { Type of the } \\
\text { Inorganic salts }\end{array}$ & $\begin{array}{l}\text { Concentration } \\
\text { of salt }(\mathrm{ppm})\end{array}$ & $\begin{array}{l}\text { Rate constant } \\
\left(\times 10^{-2} / \mathrm{min}\right)\end{array}$ & $\begin{array}{l}\text { Quantum } \\
\text { efficiency }(\Phi) \\
\left(\times 10^{-12} \mathrm{ppm} /\right. \\
\text { Einstein })\end{array}$ \\
\hline In the absence of any salt & - & 3.84 & 24.3 \\
$\mathrm{Na}_{2} \mathrm{CO}_{3}$ & 10 & 2.92 & 19.68 \\
& 25 & 1.68 & 15.06 \\
& 50 & 1.68 & 15.06 \\
$\mathrm{NaHCO}_{3}$ & 10 & 1.77 & 15.55 \\
& 25 & 1.35 & 13.12 \\
& 50 & 1.38 & 13.36 \\
$\mathrm{Na}_{2} \mathrm{SO}_{4}$ & 10 & 0.94 & 10.2 \\
& 25 & 0.69 & 8.74 \\
& 50 & 1.12 & 11.66 \\
$\mathrm{NaCl}$ & 10 & 1.31 & 12.87 \\
& 25 & 1.05 & 11.17 \\
& 50 & 1.12 & 11.66 \\
$\mathrm{KNO}_{3}$ & 10 & 2.25 & 17.49 \\
& 25 & 2.99 & 19.92 \\
& 50 & 2.99 & 19.92 \\
\hline
\end{tabular}

Experimental condition: $\left[\mathrm{Fe}^{0}\right]=10 \mathrm{mg} / 250 \mathrm{ml},[\mathrm{BB}]=25 \mathrm{ppm},[\mathrm{HP}]=25 \mathrm{ppm}$ or $[\mathrm{APS}]=10 \mathrm{ppm}$ and $\mathrm{pH} 3$.

[Anions $]<\left[\mathrm{H}_{2} \mathrm{O}_{2}\right] \quad \mathrm{SO}_{4}^{2-}>\mathrm{Cl}^{-}>\mathrm{HCO}_{3}^{-}>\mathrm{NO}_{3}^{-}>\mathrm{CO}_{3}^{2-}$

[Anions $]=\left[\mathrm{H}_{2} \mathrm{O}_{2}\right] \quad \mathrm{SO}_{4}^{2-}>\mathrm{Cl}^{-}>\mathrm{HCO}_{3}^{-}>\mathrm{CO}_{3}^{2-}>\mathrm{NO}_{3}^{-}$

$[$ Anions $]>\left[\mathrm{H}_{2} \mathrm{O}_{2}\right] \quad \mathrm{SO}_{4}^{2-} \sim \mathrm{Cl}^{-}>\mathrm{HCO}_{3}^{-}>\mathrm{CO}_{3}^{2-}>\mathrm{NO}_{3}^{-}$

Similarly for APS as an oxidant:

[Anions] $<$ [APS $] \quad \mathrm{HCO}_{3}^{-} \sim \mathrm{Cl}^{-}>\mathrm{SO}_{4}^{2-}>\mathrm{CO}_{3}^{2-}>\mathrm{NO}_{3}^{-}$

[Anions $]=[\mathrm{APS}] \quad \mathrm{Cl}^{-}>\mathrm{SO}_{4}^{2-} \sim \mathrm{HCO}_{3}^{-} \sim \mathrm{CO}_{3}^{2-}>\mathrm{NO}_{3}^{-}$

[Anions] $>$ [APS] $\mathrm{SO}_{4}^{2-}>\mathrm{Cl}^{-} \sim \mathrm{CO}_{3}^{2-}>\mathrm{HCO}_{3}^{-}>\mathrm{NO}_{3}^{-}$

In the case of APS as an oxidant, the capacity to quench the hydroxyl radical is least for the nitrate anion over the range of

Table 4

Rate constant and process efficiency in the presence of various inorganic anions for the process $\mathrm{Fe}^{0} / \mathrm{APS} / \mathrm{UV}$.

\begin{tabular}{lrll}
\hline $\begin{array}{l}\text { Type of the } \\
\text { inorganic salts }\end{array}$ & $\begin{array}{c}\text { Concentration } \\
\text { of salt }(\mathrm{ppm})\end{array}$ & $\begin{array}{l}\text { Rate constant } \\
\left(\times 10^{-2} / \mathrm{min}\right)\end{array}$ & $\begin{array}{l}\text { Quantum } \\
\text { efficiency }(\Phi) \\
\left(\times 10^{-12} \mathrm{ppm} /\right. \\
\text { Einstein })\end{array}$ \\
\hline In the absence of any salt & - & 7.91 & 48.6 \\
$\mathrm{Na}_{2} \mathrm{CO}_{3}$ & 5 & 2.83 & 27.21 \\
& 10 & 2.69 & 26.24 \\
& 20 & 2.04 & 21.38 \\
$\mathrm{NaHCO}_{3}$ & 5 & 1.68 & 18.95 \\
& 10 & 2.62 & 27.75 \\
& 20 & 2.34 & 24.30 \\
$\mathrm{Na}_{2} \mathrm{SO}_{4}$ & 5 & 2.60 & 25.75 \\
& 10 & 2.60 & 25.27 \\
& 20 & 1.10 & 13.60 \\
$\mathrm{NaCl}^{2}$ & 5 & 1.68 & 18.46 \\
& 10 & 1.88 & 20.41 \\
$\mathrm{KNO}_{3}$ & 20 & 1.88 & 20.41 \\
& 5 & 3.36 & 30.13 \\
& 10 & 3.89 & 32.56 \\
& 20 & 5.73 & 38.88
\end{tabular}

Experimental condition: $\left[\mathrm{Fe}^{0}\right]=10 \mathrm{mg} / 250 \mathrm{ml},[\mathrm{BB}]=25 \mathrm{ppm},[\mathrm{HP}]=25 \mathrm{ppm}$ or $[\mathrm{APS}]=10 \mathrm{ppm}$ and $\mathrm{pH} 3$.

$$
\begin{aligned}
& \mathrm{Fe}^{2+}+\mathrm{Cl}^{-} \leftrightarrow \mathrm{FeCl}^{+} \\
& \mathrm{Fe}^{3+}+\mathrm{Cl}^{-} \leftrightarrow \mathrm{FeCl}^{2+} \\
& \mathrm{Fe}^{3+}+2 \mathrm{Cl}^{-} \leftrightarrow \mathrm{FeCl}_{2}^{+} \\
& \mathrm{FeCl}_{2}^{+} \rightarrow \mathrm{Fe}^{2+}+\mathrm{Cl}_{2}^{{ }^{-}} \\
& \mathrm{Fe}^{2+}+\mathrm{Cl}^{\cdot} \rightarrow \mathrm{Fe}^{3+}+\mathrm{Cl}^{-} \\
& \mathrm{Fe}^{2+}+\mathrm{Cl}^{\cdot} \rightarrow \mathrm{FeCl}^{2+}+\mathrm{Cl}^{-} \\
& \mathrm{Cl}^{-}+\mathrm{HO} \rightarrow\left[\mathrm{ClOH}^{-}\right. \\
& {\left[\mathrm{ClOH}^{-}\right.} \\
& {\left[\mathrm { HClOH } ^ { - } \rightarrow \mathrm { H } ^ { + } \rightarrow \left[\mathrm{Cl}_{+} \mathrm{H}_{2} \mathrm{O}\right.\right.} \\
& \mathrm{ClOH}^{\cdot}+\mathrm{H}_{2} \mathrm{O}_{2} \rightarrow \mathrm{HO}_{2}^{\cdot}+\mathrm{Cl}^{-}+\mathrm{H}^{+} \\
& \mathrm{Cl}_{2}^{\cdot}+\mathrm{H}_{2} \mathrm{O}_{2} \rightarrow \mathrm{HO}_{2}^{\cdot}+2 \mathrm{Cl}^{-}+\mathrm{H}^{+} \\
& \mathrm{Cl}^{-}+\mathrm{HO}^{\cdot}+\mathrm{H}^{+} \rightarrow \mathrm{Cl}^{\cdot}+\mathrm{H}_{2} \mathrm{O}
\end{aligned}
$$

Scheme 1. Additional reactions of chloride anion in Fenton's reactions.

concentrations used. The calculated rate constant and process efficiency are shown in the Tables 3 and 4 which suggest that all the inorganic anions had a negative effect on the degradation rate.

\subsection{Kinetic studies}

The calculation of apparent first order rate constant for the degradation of $\mathrm{BB}$ using various oxidation processes for the time period of $30 \mathrm{~min}$ is shown in the Table 5 and Fig. 5 . The dye solution was degraded to an extent of 25, 45 and 32 percent for the processes $\mathrm{Fe}^{0} /$ dark, $\mathrm{Fe}^{0} / \mathrm{APS} /$ dark and $\mathrm{Fe}^{0} / \mathrm{H}_{2} \mathrm{O}_{2} /$ dark, respectively. The dye degradation for the process $\mathrm{Fe}^{\mathrm{o}} /$ dark is due to the formation of iron complexes. The iron ions react with dye molecules preferably with the reactive sites of BB which renders the cleavage of azo chromophore (Park and Choi, 2003). The presence of oxidants like HP or APS increases the degradation efficiency compared to the $\mathrm{Fe}^{0} /$ dark process. Iron powder under acidic condition gets oxidized to $\mathrm{Fe}^{2+}$ ions, which further reacts with $\mathrm{H}_{2} \mathrm{O}_{2}$ or APS to generate hydroxyl radicals as already mentioned in Eqs. (8) and (9). In the presence of oxidants alone (in the dark condition), dye degradation was almost negligible. Upon UV irradiation for $30 \mathrm{~min}$, the degradation efficiency for the

$$
\begin{aligned}
& \mathrm{Fe}^{2+}+\mathrm{SO}_{4}{ }^{2-} \leftrightarrow \mathrm{FeSO}_{4} \\
& \mathrm{Fe}^{3+}+\mathrm{SO}_{4}{ }^{2-} \leftrightarrow \mathrm{FeSO}_{4}{ }^{+} \\
& \mathrm{Fe}^{3+}+2 \mathrm{SO}_{4}{ }^{2-} \leftrightarrow \mathrm{FeSO}_{4}{ }^{2-} \\
& \mathrm{FeSO}_{4}{ }^{+} \rightarrow \mathrm{Fe}^{2+}+\mathrm{SO}_{4}{ }^{-\cdot} \\
& \mathrm{SO}_{4}{ }^{-\cdot}+\mathrm{H}_{2} \mathrm{O}_{2} \rightarrow \mathrm{SO}_{4}{ }^{2-}+\mathrm{HO}_{2}{ }^{-\cdot}+\mathrm{H}^{+} \\
& \mathrm{SO}_{4}{ }^{2-}+\mathrm{OH}^{\cdot} \rightarrow \mathrm{SO}_{4}{ }^{-\cdot}+\mathrm{OH}^{-}
\end{aligned}
$$

Scheme 2. Additional reactions of sulfate anion in Fenton's reactions.

$$
\begin{aligned}
& \mathrm{NO}_{3}{ }^{-}+\mathrm{OH}^{\cdot} \rightarrow \mathrm{NO}_{3}{ }^{-}+\mathrm{OH}^{-} \\
& \mathrm{CO}_{3}{ }^{2-}+\mathrm{OH}^{\cdot} \rightarrow \mathrm{OH}^{-}+\mathrm{CO}_{3}{ }^{-\cdot} \\
& \mathrm{HCO}_{3}{ }^{-}+\mathrm{OH}^{\cdot} \rightarrow \mathrm{OH}^{-}+\mathrm{HCO}_{3}{ }^{-.}
\end{aligned}
$$

Scheme 3. Scavenging effect of nitrate, carbonate and bicarbonate anions. 


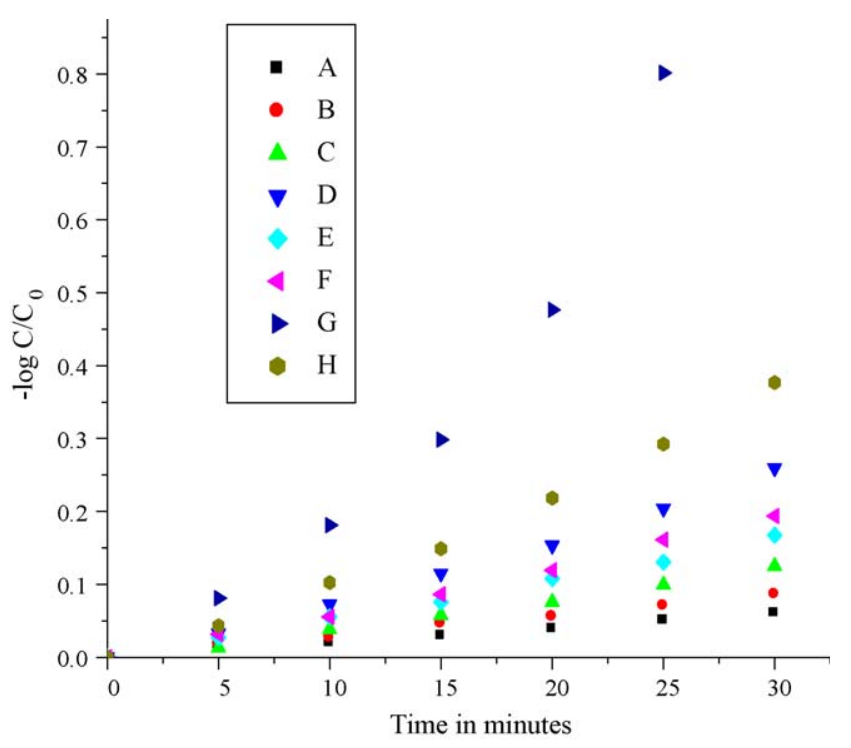

Fig. 5. Plot of $-\log C / C_{0}$ versus time for the degradation of $\mathrm{BB}$ using various oxidation processes. Experimental condition: $\left[\mathrm{Fe}^{0}\right]=10 \mathrm{mg} / 250 \mathrm{ml}$, $[\mathrm{BB}]=25 \mathrm{ppm}$, $[\mathrm{HP}]=25 \mathrm{ppm}$ or $[$ APS $]=10 \mathrm{ppm}$ and $\mathrm{pH} 3:$ (A) UV/APS, (B) $\mathrm{UV} / \mathrm{H}_{2} \mathrm{O}_{2}$, (C) $\mathrm{Fe}^{0} /$ dark, (D) $\mathrm{Fe}^{0} /$ APS/dark, (E) $\mathrm{Fe}^{0} / \mathrm{H}_{2} \mathrm{O}_{2} /$ dark, (F) $\mathrm{Fe}^{0} / \mathrm{UV}$, (G) $\mathrm{Fe}^{0} / \mathrm{APS} / \mathrm{UV}$ and (H) $\mathrm{Fe}^{0} / \mathrm{H}_{2} \mathrm{O}_{2}$ UV.

above processes increased up to 36,100 and 58 percent, respectively. The enhancement in the efficiency of $\mathrm{Fe}^{0} / \mathrm{UV}$ process is due to the fact that iron complexes formed in the dark undergoes cleavage on UV irradiation and the iron ions can return to iron regeneration cycle for active participation in the cyclic photoFenton process (Kavitha and Palanivelu, 2004). The generation of hydroxyl radicals by the oxidants alone and the photolysis of dye molecules additionally contribute to the overall enhancement in the degradation process. In addition, photo-reduction of $\mathrm{Fe}^{3+}$ to $\mathrm{Fe}^{2+}$ ions takes place at a faster rate on the iron surface in APFP as shown in Eq. (17).

The rate constant calculated for $\mathrm{H}_{2} \mathrm{O}_{2} / \mathrm{UV}$ process is 1.4 times higher than APS/UV process. This difference can be attributed to the direct photolysis of $\mathrm{H}_{2} \mathrm{O}_{2}$ which yields two hydroxyl radicals, while one hydroxyl radical is generated along with proton by the APS as shown in Eq. (15).

The rate constant calculated for the process $\mathrm{Fe}^{0} / \mathrm{H}_{2} \mathrm{O}_{2} / \mathrm{UV}$ is 2.42 times higher than that of $\mathrm{Fe}^{\mathrm{O}} / \mathrm{H}_{2} \mathrm{O}_{2} /$ dark. While the rate constant calculated for the process $\mathrm{Fe}^{0} / \mathrm{APS} / \mathrm{UV}$ is 3.75 times higher compared to the same process in dark condition. The higher efficiency observed for APFP under illumination is mainly due to faster back photo-reduction of $\mathrm{Fe}^{3+}$ to $\mathrm{Fe}^{2+}$ ions. The reduced $\mathrm{Fe}^{2+}$ ions can react with oxidants generating hydroxyl radicals thereby increasing the efficiency of the process. The rate constant for the

Table 5

Percentage degradation and rate constant for the degradation of BB using various oxidation processes for a time period of $30 \mathrm{~min}$.

\begin{tabular}{lcl}
\hline Oxidation processes & $\begin{array}{l}\text { Percentage } \\
\text { degradation }\end{array}$ & $\begin{array}{l}\text { Rate constant from }-\log C / C_{0} \\
\text { versus time plot }\left(\times 10^{-2} \mathrm{~min}\right)\end{array}$ \\
\hline UV/APS & 13 & 0.43 \\
UV/HP & 18 & 0.62 \\
$\mathrm{Fe}^{0} /$ dark & 25 & 0.99 \\
$\mathrm{Fe}^{0} / \mathrm{APS} /$ dark & 45 & 2.04 \\
$\mathrm{Fe}^{0} / \mathrm{HP} /$ dark & 32 & 1.24 \\
$\mathrm{Fe}^{0} / \mathrm{UV}$ & 36 & 1.51 \\
$\mathrm{Fe}^{\mathrm{O}} / \mathrm{APS} / \mathrm{UV}$ & 100 & 7.91 \\
$\mathrm{Fe}^{\mathrm{O}} / \mathrm{HP} / \mathrm{UV}$ & 58 & 3.01 \\
\hline
\end{tabular}

Experimental condition: $\left[\mathrm{Fe}^{0}\right]=10 \mathrm{mg} / 250 \mathrm{ml},[\mathrm{BB}]=25 \mathrm{ppm},[\mathrm{HP}]=25 \mathrm{ppm}$ or [APS $]=10 \mathrm{ppm}$ and $\mathrm{pH} 3$.<smiles>Nc1ccc(N=Nc2cccc(N=Nc3ccc(N)cc3N)c2)c(N)c1</smiles>

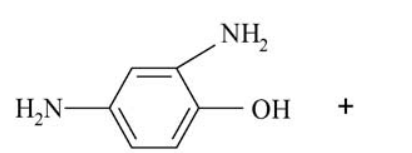

(1)

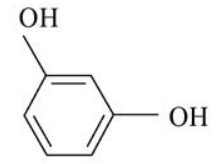

(2)
Scheme 4. Oxidation of BB by hydroxyl radicals.

kinetics of degradation using various oxidation processes follows the order:

$\mathrm{Fe}^{0} /$ APS $/ \mathrm{UV}>\mathrm{Fe}^{0} / \mathrm{H}_{2} \mathrm{O}_{2} / \mathrm{UV}>\mathrm{Fe}^{0} /$ APS $/$ dark $>$

$$
\mathrm{Fe}^{0} / \mathrm{UV}>\mathrm{Fe}^{0} / \mathrm{H}_{2} \mathrm{O}_{2} / \text { dark }>\mathrm{Fe}^{0} / \text { dark }>\mathrm{H}_{2} \mathrm{O}_{2} / \mathrm{UV}>\text { APS } / \mathrm{UV} \text {. }
$$

It is interesting to note that the rate constant calculated for the process $\mathrm{Fe}^{0} /$ dark is 1.6 times higher than the $\mathrm{H}_{2} \mathrm{O}_{2} / \mathrm{UV}$. The hydroxyl radicals generated from the direct photolysis of $\mathrm{H}_{2} \mathrm{O}_{2}$ attacks at the active site of azo chromophore resulting in the oxidation of azo bonds yielding hydroxylated products as shown in Scheme 4 . The azo bonds can be easily reduced to amines on the metal surface even in the dark under aerated conditions (Scheme 5) (Zongshan et al., 2008). The reduction of azo bonds takes place at a faster rate compared to the oxidation of azo bonds. These results suggest that iron powder is an efficient catalyst in heterogeneous photocatalysis.

\subsection{Recycling efficiency of iron powder}

The efficiency of iron powder was tested by the recycling it for the degradation of $\mathrm{BB}$ with respect to the optimized conditions as reported. Experiments were carried out for $1 \mathrm{~h}$ duration with $\mathrm{H}_{2} \mathrm{O}_{2}$ or APS as oxidants. After each run fresh dye solution along with the oxidant is replaced in the reactor using the same iron powder after washing with distilled water. When HP is used as oxidant the complete degradation of BB was achieved in the first two cycles as shown in Fig. 6. For the third to fifth run the efficiency was reduced to 90 percent. From sixth to tenth run the efficiency further decreased and only 52 percent of degradation could be achieved. Beyond this cycle the catalyst surface showed resistance for the degradation of BB. In the case of APS, the efficiency of the iron powder is retained for the first two runs. From third to fifth run, the efficiency decreased to 80 percent. Beyond fifth run the efficiency drastically decreased and for the tenth run only 15 percent of the dye could be degraded. Hence it can be concluded that iron powder retained its recycling efficiency with HP compared to APS. Iron powder undergoes dissolution with subsequent runs in the presence of APS, generating excess $\mathrm{Fe}^{2+}$ ions in the solution. With subsequent runs, the generation of hydroxyl radicals becomes less and hence the $\mathrm{Fe}^{2+}$ might act as hydroxyl radical scavenger.

\section{GC-MS analysis}

The solution after 30 min of UV irradiation shows two $m / z$ peaks at 108 (relative abundance [RA]: 32 , retention time [Rt]: $12.4 \mathrm{~min}$ ) and 114 (RA: 74; Rt: $18.6 \mathrm{~min}$ ) corresponding to the intermediates 4-amino aniline (3) and 2-hydroxy, 4-amino aniline (4) which resulted due to the reduction of azo bonds on the iron surface. The 


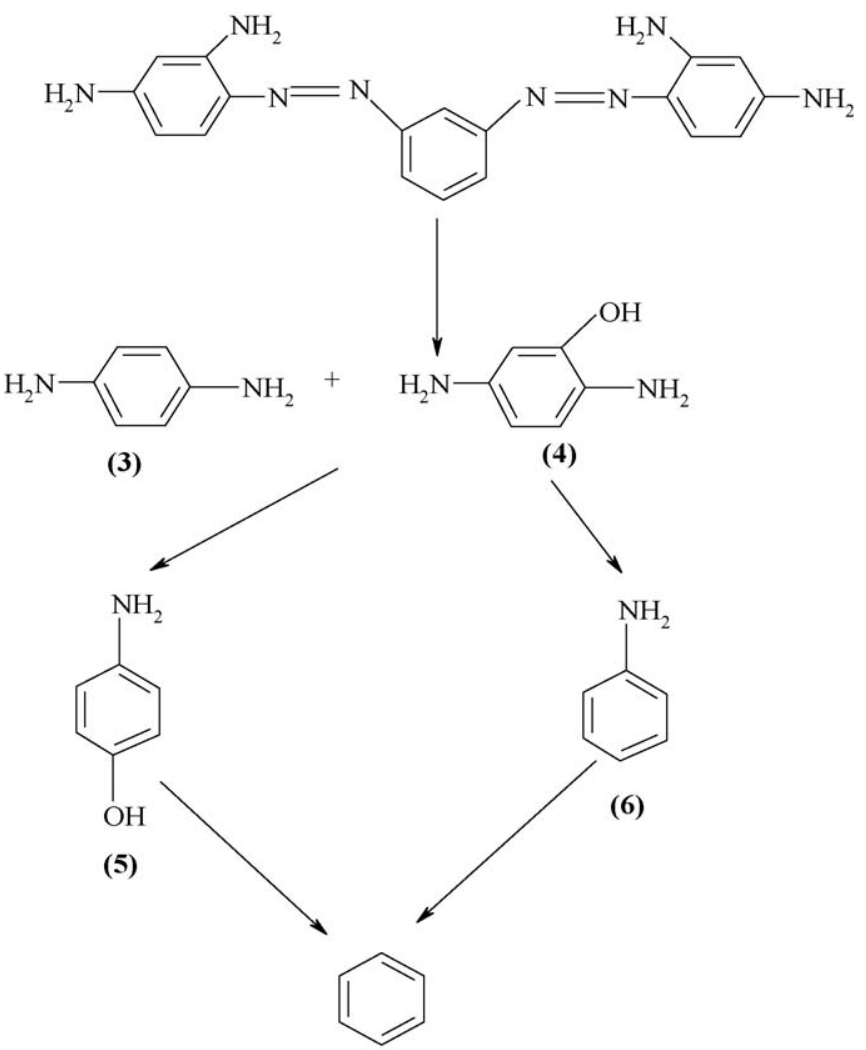

(7)<smiles>C[PH2+]([O-])C(=O)O</smiles>

Scheme 5. Probable degradation mechanism for BB by APFP.

solution after $40 \mathrm{~min}$ of irradiation shows four $\mathrm{m} / \mathrm{z}$ peaks at 109 (RA: 62; Rt: $8.8 \mathrm{~min}$ ) and 93 (RA: 56; Rt: 16.4) corresponding to the formation of 4-amino phenol (5) and aniline (6). The loss of substituent $-\mathrm{NH}_{2}$ as $-\mathrm{NH}_{2} \mathrm{OH}$ and $-\mathrm{OH}$ as $\mathrm{H}_{2} \mathrm{O}$ in the intermediate (3) and (4) by the hydroxyl radical attack leads to the formation of (5) and (6). After 50 min of UV irradiation, the solution showed

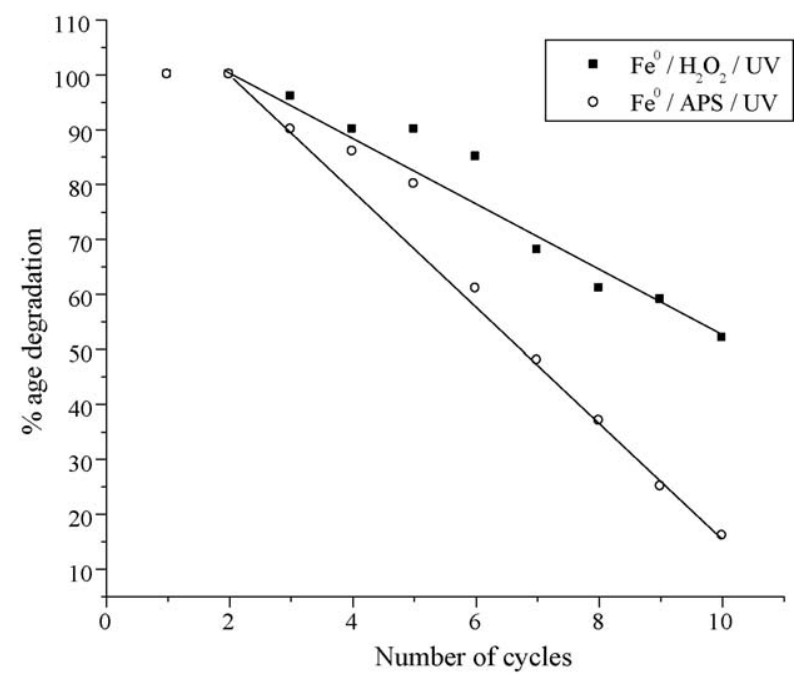

Fig. 6. Evaluation of recycling efficiency of iron powder. Experimental condition: $\left[\mathrm{Fe}^{0}\right]=10 \mathrm{mg} / 250 \mathrm{ml},[\mathrm{BB}]=25 \mathrm{ppm},[\mathrm{HP}]=25 \mathrm{ppm}$ or $[\mathrm{APS}]=10 \mathrm{ppm}$ and $\mathrm{pH} 3$. intense $m / z$ peak at 78 (RA: 84; Rt: 20.2 min) corresponding to the formation of benzene (7), with subsequent hydroxyl radical attack leads to complete mineralization which was confirmed by the absence of chromatogram in GC. The probable degradation pathway is shown in Scheme 5.

\section{Conclusion}

ZVMI was used as catalyst in the photo-Fenton process for complete degradation of di azo dye BB in aqueous medium. The influences of several reaction parameters like concentration of dye/oxidants $/ \mathrm{Fe}^{0}$ are studied and the conditions are optimized. The process $\mathrm{Fe}^{0} / \mathrm{H}_{2} \mathrm{O}_{2} / \mathrm{UV}$ retained its efficiency even for higher concentration of BB. The effect of inorganic anions like $\mathrm{NaCl}$, $\mathrm{KNO}_{3}, \mathrm{Na}_{2} \mathrm{SO}_{4}, \mathrm{Na}_{2} \mathrm{CO}_{3}$ and $\mathrm{NaHCO}_{3}$ at different concentrations is studied in detail. $\mathrm{SO}_{4}{ }^{2-}$ and $\mathrm{Cl}^{-}$retard the efficiency of the process by scavenging of hydroxyl radicals and also by forming complexes with iron ions. This process reduces the generation of hydroxyl radicals from Fenton reagent. While $\mathrm{CO}_{3}{ }^{2-}, \mathrm{NO}^{3-}$ and $\mathrm{HCO}_{3}{ }^{-}$compete for hydroxyl radicals along with dye molecules which negatively affect the degradation rate. Iron powder retained its recycling efficiency for the first four runs in case of both the oxidants. However for the subsequent runs, the efficiency was retained in the case of HP compared to APS. The degradation was followed by UV-vis and GC-MS techniques.

\section{Acknowledgement}

Financial assistance from UGC Major Research Project (20072010) is acknowledged.

\section{References}

Barbusinski, K. and J. Majewski, "Degradation of Azo Dye Acid Red 18 by Fenton Reagent in the Presence of Iron Powder," Pol. J. Environ. Stud., 12, 151 (2003).

Baxendale, J. H. and J. A. Wilson, "The Photolysis of Hydrogen Peroxide at High Light Intensities," Trans. Faraday Soc., 53, 344 (1957).

Bremner, D. H., A. E. Burgess, D. Houllemare, and K. C. Namkung, "Phenol Degradation Using Hydroxyl Radicals Generated from Zero Valent Iron and Hydrogen Peroxide," Appl. Catal. B: Environ., 63, 15 (2006).

Devi, L. G., S. G. Kumar, K. M. Reddy, and C. Munikrishnappa, "Photodegradation of Methyl Orange an Azo Dye by Advanced Fenton Process Using Zero Valent Metallic Iron: Influence of Various Reaction Parameters and Its Degradation Mechanism," $J$. Hazard. Mater., 164, 459 (2009).

Dong, Y., J. Chen, C. Li, and H. Zu, "Decolorisation of Three Azo Dyes in Water by Photocatalysis of $\mathrm{Fe}(\mathrm{III})-\mathrm{Oxalate}$ Complexes $/ \mathrm{H}_{2} \mathrm{O}_{2}$ in the Presence of Inorganic Salts," Dyes Pigments, 73, 261 (2007).

Dutta, K., S. Mukhopadhyay, S. Bhattacharjee, and B. Chaudhuri, "Chemical Oxidation of Methylene Blue using Fenton-like Reactions," J. Hazard. Mater., 84, 57 (2001)

Elmorsi, T. M., Y. M. Riyad, Z. H. Mohamed, and Bary, H. M. H. A. B. "Decolorization of Mordant Red 73 Azo Dye in Water Using $\mathrm{H}_{2} \mathrm{O}_{2} / \mathrm{UV}$ and Photo-Fenton Treatment," J. Hazard. Mater., 174, 352 (2010).

Kang, S. F., C. H. Liao, and M. C. Chen, "Preoxidation and Coagulation of Textile Wastewater by the Fenton Process," Chemosphere, 46, 923 (2002).

Katsumata, H., S. Kawabe, S. Kaneco, T. Suzuki, and K. Ohta, "Degradation of Bisphenol A in Water by the Photo-Fenton Reaction," J. Photochem. Photobiol. A: Chem., 162 297 (2004).

Kavitha, V. and K. Palanivelu, "The Role of Ferrous Ion in Fenton and Photo-Fenton Process for the Degradation of Phenol," Chemosphere, 55, 1235 (2004).

Kusic, H., N. Koprivanac, A. L. Bozic, and I. Selanec, "Photo-assisted Fenton Type Processes for the Degradation of Phenol: A Kinetic Study," J. Hazard. Mater., 136 632 (2006).

Lucking, F., H. Koser, A. Ritter, and M. Jank, "Iron Powder and Graphite and Activated Carbon as a Catalyst for the Oxidation of 4-Chlorophenol with Hydrogen Peroxide," Water Res., 32, 2607 (1998)

Neamtu, M., A. Yediler, I. Siminiceanu, and A. Kettrup, "Oxidation of Commercial Reactive Azo Dye Aqueous Solutions by the Photo-Fenton and Fenton-like Process," J. Photochem. Photobiol. A: Chem., 161, 87 (2003).

Neta, P., V. Madhava, H. Zemel, and R. W. Fessmdem, "Rate Constants and Mechanism of Reaction of Sulfate Radicals with Aromatic Compounds," J. Am. Chem. Soc., 99 163 (1977).

Ntampegliotis, K., A. Riga, V. Karayannis, V. Bontozoglou, and G. Papapolymerou, "Decolorisation Kinetics of Portion H-Exl Dyes from Textile Dyeing Using Fenton-like Reactions," J. Hazard. Mater., 136, 75 (2006). 
Orozco, S. L., E. R. Bandala, C. A. A. Bulnes, B. Serrano, R. S. Parra, and I. H. Perez, "Effect of Iron Salt on The Color Removal of Water Containing the Azo-Dye Reactive Blue Using Photo-assisted $\mathrm{Fe}(\mathrm{II}) / \mathrm{H}_{2} \mathrm{O}_{2}$ and $\mathrm{Fe}(\mathrm{III}) / \mathrm{H}_{2} \mathrm{O}_{2}$ Systems," J. Photochem. Photobiol. A: Chem., 198, 144 (2008).

Pappolymerou, P., K. Ntampegliotis, A. Riga, V. Karayannis, and K. Soutsas, "Effect of System Parameters and of Inorganic Salts on the Decolorisation and Degradation of Procion $\mathrm{H}$-exl Dyes. Comparison of $\mathrm{H}_{2} \mathrm{O}_{2} / \mathrm{UV}$, Fenton, $\mathrm{UV} /$ Fenton, $\mathrm{TiO}_{2} / \mathrm{UV}$ and $\mathrm{TiO}_{2} /$ $\mathrm{UV} / \mathrm{H}_{2} \mathrm{O}_{2}$ Processes," Desalination, 211, 72 (2007).
Park, H. and W. Choi, "Visible Light and Fe(III)-mediated Degradation of Acid Orange 7 in the Absence of $\mathrm{H}_{2} \mathrm{O}_{2}$," J. Photochem. Photobiol. A: Chem., 159, 241 (2003).

Zhao, X. K., G. P. Yeng, Y. J. Wang, and X. C. Gao, "Photochemical Degradation of Dimethyl Phthalate by Fenton Reagent," J. Photochem. Photobiol. A: Chem., 161, 215 (2004).

Zongshan, Z., L. Jingju, T. Shao, Z. Qunfang, H. Jingtian, and J. Guibin, “Rapid Decolorisation of Water Soluble Azo Dyes by Nanosized Zero Valent Iron Immobilized on the Exchange Resin," Sci. China Ser. B Chem., 51, 186 (2008). 